Erratum

\title{
Erratum: Moralee, Jason. It's in the Water: Byzantine Borderlands and the Village War. Humanities 2018, 7,86
}

\author{
Jason Moralee \\ Department of History, University of Massachusetts Amherst, Amherst, MA 01003, USA; \\ jmoralee@history.umass.edu
}

Received: 3 July 2019; Accepted: 3 July 2019; Published: 5 July 2019

The author would like to make the following changes to the published paper (Moralee 2018):

On page 11, in the last paragraph, the following sentence:

To borrow an observation from the Marxist historian Santo Mazzarino, empires can be the 'object of infinite love as well as infinite hatred.'

should read as follows:

To borrow an observation from the historian Santo Mazzarino, empires can be the 'object of infinite love as well as infinite hatred.'

In References Section, the following reference:

Laniado, Avshalom. 1996. $\Sigma v \vee \tau \varepsilon \lambda \varepsilon \sigma \tau \dot{\eta} \sigma$ : Notes sur un terme fiscal surinterprété. Journal of Juristic Papyrology 26: 23-51.

should read as follows:

Laniado, Avshalom. 1996. $\Sigma v \vee \tau \varepsilon \lambda \varepsilon \sigma \tau \eta \dot{s}$ : Notes sur un terme fiscal surinterprété. Journal of Juristic Papyrology 26: 23-51.

The author apologizes for any inconvenience caused to the readers by these changes. The changes do not affect the scholarly results.

\section{References}

Moralee, Jason. 2018. It's in the Water: Byzantine Borderlands and the Village War. Humanities 7: 86. [CrossRef] 